\title{
PROJETO POLÍTICO E SISTEMATIZAÇÃO DO ENSINO PÚBLICO BRASILEIRO NO SÉCULO XIX
}

\author{
ANDRÉ LUIZ PAULILO \\ Escola Municipal de Ensino Fundamental Altino Arantes - São Paulo \\ paulilo@usp.br \\ RESUMO
}

Este artigo situa a concepção de sistema público de ensino no quadro do pensamento politico de Rui Barbosa e do liberalismo republicano de João Köpke. Depois de apresentar as posições com que consideram a questão, o texto investiga os argumentos desenvolvidos na prática parlamentar de Rui Barbosa e na carreira profissional de João Köpke, para compreender as relações que os dois autores mantiveram com os critérios de reforma da instrução pública no século XIX. REFORMADOENSINO-HISTÓRIADAEDUCAÇÃO-EDUCAÇÃOPÚBLICA

\section{ABSTRACT}

POLITICAL PROJECTAND SYSTEMATIZATIONOFBRAZILIANPUBLIC-SCHOOLEDUCATION IN THE $19^{\text {th }}$ CENTURY. This article situates the concept of public-school education system within the framework of Rui Barbosa's political thought and João Köpke's republican liberalism. After presenting their views on this issue, the text explores the arguments developed during Rui Barbosa's parliamentary practice and João Köpke's professional carrier to try to understand the relationship both authors kept with public education reform criteria in the $19^{\text {th }}$ century. EDUCATIONAL REFORM - HISTORY OF EDUCATION - PUBLIC EDUCATION 
No Brasil, com o século XIX a educação pública emergiu, de fato, para o pensamento social como instrumento por excelência da formaçãa dos cidadãos. $\mathrm{E}$ o fez num quadro político particularmente interessante. Apeado do poder em I 868 com a queda do gabinete Zacarias, o partido liberal passaria por uma ostensiva viragem até o fim daquela década.

Para Alfredo Bosi este foi o período em que os liberais passaram do emperrado e escravista regresso agromercantil, estratégia política dos liberais moderados em defesa dos cafeicultores registrada entre as décadas de 1830 e 1860, para um reformismo arejado no valor do trabalho livre. Assim, segundo a análise (Bosi, 1989 , p. 194-245), se para os "novos" liberais, pós I868, a Constituição de I824, simulacro liberal, privilegiava a realidade do modelo em detrimento do modelo da realidade, no período anterior criou-se o mito da sua intocabilidade, segundo o qual os conservadores se proclamavam constitucionalistas em oposição à aspiração absolutista do Primeiro Reinado e sob o qual erigiram-se, ainda seguindo as observações de Bosi, dois novos tipos políticos: os liberais conservadores e os liberais constitucionais. Todos eles, no entanto, podem ser reduzidos ao denominador comum de escravocratas, uma vez que aderem de algum modo à idéia de que o trabalho escravo era um fator estrutural da economia.

Esse primeiro liberalismo brasileiro, escravocrata, conviveu com uma preocupação especialmente voltada à avaliação e aos exames de acesso ao ensino secundário e ao superior. Em que se pese toda a discussão em torno dos métodos de ensino, presente em diversos textos oficiais', os exames pareciam ser, segundo a memória docente, a maior preocupação daqueles que procuravam a instrução elementar. Como demonstrou Maria Cecília Cortez Christiano de Souza, tratavase de ver na demanda escolar o imediatismo de uma concepção estreita de cultura que, por não valorizar a cultura letrada, atingia em cheio o magistério - baixos salários, má formação pedagógica, ocupações secundárias -, ao fazer da instrução primária tão-somente um meio para adquirir o direito à matrícula nos cursos secundários e superior (Souza, 2000, p. I00-101).

É ainda a mesma autora quem observou no relatório e no conjunto de Pareceres de Rui Barbosa, que propõem a reforma do ensino primário, redigida em 1882, os artifícios utilizados pelo parlamentar para condenar a instrução pública

I O Arquivo Geral da Cidade do Rio de Janeiro possui uma série de documentos que indicam o sentido dessa discussão: Aguiar ( 187 I), Carvalho (I880), Marconi (I 880), Carvalho (I 880), Constant (1882). 
imperial. Suas análises caracterizam bem a complexidade da prática educacional, obliterada dos Pareceres por Rui Barbosa, quando toma a memorização mecânica como espécime do gênero de instrução usual no país. Tratava-se, diz a autora, não de um método de ensino como fazia crer Rui Barbosa, mas de um modelo de cultura, no qual os textos serviam como cânone para repetições exatas: ensinava-se segundo esse modelo porque era a maneira pela qual os alunos seriam avaliados. Ela notou, por conseguinte, que ao contrário do que pensava Rui Barbosa, a memorização mecânica não era entendida pelos professores do império como um método de ensino,

...além de atender a demanda pelos exames das escolas superiores, vinha substituir muitas vezes, ou mesmo suprir, não a ausência de conhecimento de métodos de ensino, mas a raridade de livros, outras vezes, a ausência de conhecimento do conteúdo das próprias disciplinas. (Souza, p. 97)

O que pareceu ser a Rui Barbosa (1946) um "enorme pecado contra a pátria e contra a humanidade", era pensado pelos professores primários da instrução pública como um padrão de ensino utilizado por causa de sua aplicabilidade às necessidades e interesses dos alunos, "uma forma um tanto espúria de democratização" (Souza, 2000, p. 97).

Entretanto, a reação que os Pareceres de Rui Barbosa impingiram ao pensamento dos republicanos preocupados, de um modo ou de outro, com a instrução pública entre os últimos anos do Império e as primeiras décadas republicanas, conviveu com um novo liberalismo. Em I882, os padrões políticos conservadores que serviram para conduzir a canais adequados os "antigos liberais" - por meio de um programa consensual que subestimava as divergências sérias quanto ao modo de produção, à forma de organização social e à maneira de consolidar o poder - há muito tinham dado lugar à luta liberal pela reforma eleitoral, pela separação entre a Igreja e o Estado e pela libertação do trabalho. Para retomar a análise que Bosi ( 1989 ) fez dessa transição, pode-se dizer que os usos políticos da linguagem pela qual tanto o liberalismo quanto os liberais transmitiam um imperativo lógico e um compromisso ideológico comprometidos com a manutenção do sistema escravocrata foram substituídos por uma ideologia da oposição, forjada como forma de pensar os problemas do trabalho e da cidadania. Em resposta à crise de fins dos anos da economia mercantil escravista, vieram tanto o movimento abolicionista urbano quanto a política imigrantista dos fazendeiros de São Paulo. 


\section{UM NOVO SÍMILE POLÍTICO}

Os Pareceres de Rui Barbosa devem muito a esse novo símile político. Neles há muito das inspirações liberais contidas nos manifestos e programas liberais de |868-1869, e, portanto, a mesma preocupação, a luta política. Os Pareceres não tinham somente preocupação teórica, mas, sobretudo, prática: convencer os parlamentares da necessidade de uma reforma da instrução pública mais de acordo com as realidades sociais modernas. Eram, em parte, tão só uma tentativa de aferição da realidade escolar brasileira pelos cânones da pedagogia moderna. Por outro lado, no entanto, podem ser entendidos como o prelúdio de uma trama parlamentar que visava desde logo as instituições político-sociais vigentes e, sobretudo, a forma de governar o país: a lei. Foi Roque Spencer Maciel de Barros ( 1959 ) que, ao analisar a prática política dos liberais, chamou a atenção para essa característica do jogo político, do qual dependia o trâmite das questões educacionais. Seguindo-o, chega-se a idéia de que, para os liberais, não era possível pensar realmente em progresso, social ou econômico, senão como conseqüência do progresso político; "e sob todos os aspectos a organização imperial mostra-se-lhe adversária intransigente do progresso político" (Barros, 1959, p.95). Vencer essa intransigência a partir da década de 1870, significou, para uma parte dos liberais, reconstitucionalizar a monarquia, por assim dizer, e não derrubá-la; e, para outra parte, crer que só a república seria capaz de traduzir nas instituições as legítimas aspirações liberais (Barros, p.92-93). Para os monarquistas constitucionais, tratava-se de combater os vícios do sistema forjado pela Constituição de 1824, para os republicanos liberais, entretanto, a raiz desses vícios situava-se no próprio regime político.

De ambos os modos, a liça preferida para os combates foi o campo do direito. O famoso "discurso do sorites", pronunciado em 1868, por Nabuco de Araújo, foi representativo dessa preferência. Nele, o sistema representativo, assegurado pela norma jurídica, foi profundamente questionado com relação à legitimidade de suas práticas. Assim, o ministro Nabuco de Araújo apontou suas críticas ao poder moderador nos seguintes termos:

Vede este sorites fatal, este sorites que acaba com a existência do sistema representativo; - o poder moderador pode chamar a quem quiser para organizar ministérios; esta pessoa faz a eleição, porque há de fazê-la; esta eleição faz a maioria. Eis aí está o sistema representativo do nosso país. (Araújo, apud Nabuco, 1936, p.8I) 
A mesma lógica seria utilizada para por à baila o modelo escravocrata de economia. Um ano depois do "discurso do sorites", Nabuco de Araújo, ao comentar a fórmula do Manifesto: a reforma ou a revolução, sentenciava ao gabinete Itaboray: "Digam francamente. Mas podeis resistir? Tendes forças para resistir à pressão do mundo civilizado, que nos olha e estranha como único país cristão onde existe a escravidão?" (Araújo, apud Nabuco, p. I0I).

A cisão construída por Nabuco de Araújo entre a legalidade desfrutada pelo poder moderador e o regime escravocrata e a sua situação legal, isto é, sua legitimidade social, forneceu o diagnóstico que justificou tanto a plataforma política dos radicais de 1868 quanto à reestruturação do partido liberal em 1869. Ela ainda esteve presente no manifesto e nos programas republicanos a partir de 1870. A despeito das cores partidárias tinha-se nela a medida da oposição entre o ideal e o real.

Parece ser esse o mesmo modelo de pensamento que, a partir de então, passou a organizar os discursos que procuraram promover formas de escolarização capazes de instrumentalizar mudanças sociais tendentes à modernização. É certo que tanto os monarquistas constitucionalistas quanto os republicanos liberais se utilizaram desse modelo para mobilizar suas penas contra as inquietações causadas pela situação da instrução pública não só na capital federal, mas no país. Para ambas as penas, a cisão entre a realidade social produzida pela escravidão e o ideal de cultura que se queria democratizar representava a medida da oposição entre uma realidade escolar que contabilizava inúmeros analfabetos e o ideal de uma escolarização capaz de atender plenamente toda a população em idade escolar. Essa mobilização fez difíceis os caminhos da instrução pública imperial; por um lado, denunciaram-se os empréstimos da educação jesuíta, a emulação, a disciplina do silêncio, o domínio do corpo e a memorização mecânica; por outro, criticaram-se a "oficiosidade" da instrução, o uso indevido da organização educacional pelos políticos e a precariedade das condições de ensino nas escolas ou dos seus prédios.

Os Pareceres de 1882 procederam dessa mobilização. Foram eles também um duro ataque à instrução pública elementar ministrada pela Corte. Sua eficácia legislativa foi limitada, as discussões acerca da Lei Leôncio de Carvalho seria atropelada pelos fatos que encaminhariam a proclamação da República. Sua influência, entretanto, foi mais duradoura: reduzindo o problema educacional a uma questão de método pedagógico e de infra-estrutura escolar, os Pareceres de 1882 consolidaram para as gerações republicanas a memória do ensino público elementar do tempo do Império. Uma memória que não dizia uma só palavra acerca das oportunidades do aprender, das oportunidades de entendimento do mundo em que se ia crescer ofe- 
recidas pela escolarização do Segundo Reinado, dos veios subterrâneos que ligavam a cultura que se queria democratizar com a fratura social produzida pela escravatura, segundo a interpretação que Souza (2000, p. I 0 I) fez da manobra.

Não obstante, é possível observar um outro subterfúgio em meio à mobilização. Muito ligada às elites paulistas, a organização das instituições particulares de educação na província pode ser vista como matriz de uma manobra produzida no cerne do liberalismo republicano, formulado no período de |869- |87| e |888| 889. Caracterizada pela solicitação de um modelo de educação capaz não só de estabelecer novas normas e critérios para a vida coletiva, mas sobretudo de significálos dentro de um sistema de estratificação comprometido com a conservação do funcionamento social, aquela organização expressou a intenção de impedir qualquer procedimento mais radical de reformas institucionais. Provenientes da livre iniciativa paulista, a metodologia e a orientação educacionais experimentadas na Escola Neutralidade representam bem os cálculos realizados pelas instituições para a consumação dessa solicitação. As propostas de sistematização do ensino elaboradas por João Köpke, a pedido do governo da Província do Paraná em 1884 e da recémorganizada administração do Distrito Federal em 1889, e baseadas nos princípios que regiam o instituto que fundou e dirigiu no biênio |884- | 885, ainda que possuíssem o mesmo tom dos Pareceres escritos por Rui Barbosa, não compartilhavam das mesmas convicções.

Nesses documentos há um mesmo tom normalizador no qual as regulamentações sobre a instrução pública ocupam um lugar particular: proporcionam toda sorte de estratagemas, interesses e relações de dominação destinados a fazer da escola pública um lugar de formação dos cidadãos. No geral, são representativos do esforço liberal para, longe das rupturas ou oposições violentas, corrigir a organização administrativa e as práticas escolares correntes no Segundo Império. Quanto às convicções, ambos os autores chegam a comprometer momentos fundamentais de suas respectivas idéias políticas com a enunciação de um modelo público de educação sistemática de amplo alcance social. Rui Barbosa, por exemplo, firma na obrigatoriedade escolar o próprio direito de educar do Estado. $\bigcirc$ que lhe permite concebê-lo como um direito irrecusável de todo cidadão. Köpke, por sua vez, estabelece como critério da legítima sistematização do ensino público a sua inspiração por uma livre eleição da escola, isto é, da liberdade que têm as famílias de entregar os filhos ao professor, pelo qual repele o princípio da obrigatoriedade.

No âmago dessas convicções esteve comprometido não só o ideário do modelo de cidadania desejado mas, sobretudo, a crença num determinado tipo de 
ordem social. É particularmente esse comprometimento que este artigo procura discutir nos dois autores. $\bigcirc$ objetivo da análise é distinguir as diferentes exigências políticas feitas pelos projetos de reforma da instrução de João Köpke e dos Pareceres de Rui Barbosa. Meu trabalho será o de perseguir o movimento de iniciativas que tendeu a transformar o funcionamento da instrução pública em fins do século XIX. Ele busca as diferentes causas mobilizadas pelas propostas de reforma e sistematização da educação pública entre o Império e a República no Brasil. Nesse mesmo sentido a historiografia da educação já produziu algumas referência importantes.

Um exemplo, o trabalho de Barros sobre o pensamento político de Pereira Barreto. $\bigcirc$ estudo passa pela produção intelectual e, depois, pela filiação partidária e ação política de Pereira Barreto, identificando nesse percurso o quanto a ação decorre do conhecimento, o modo pelo qual a teoria educativa subsidia tanto uma pedagogia prática, quanto uma reforma do ensino e é penetrada por circunstâncias, por eventualidades e por ações historicamente determinadas (Barros, 1967, p. 176 177, 191-192). Outro exemplo: o trabalho de Maria Lúcia Hilsdorf (1986) acerca da biografia de Rangel Pestana. Nele há a apresentação de um certo número de proposições sobre o jornalista, o político e o educador que buscou conciliar as diretrizes doutrinárias democráticas expressas no manifesto de 1870 com as reivindicações descentralizadoras e federativas do agrarismo paulista (Hilsdorf, 1986). Trata-se de um estudo sobre o movimento de idéias que não só enfrenta a questão social da educação pública, oficial e particular, como questão política, mas também dedica-se a construir, no interior da doutrina republicana, uma política de educação e uma proposta de implementação dessa política.

Minha intenção é apenas trabalhar um certo número de temas que me parecem necessários para a delimitação das diferentes utopias sociais presentes em Rui Barbosa e João Köpke, quais sejam, a sistematização de um pensamento sobre a educação popular, a sistematização do ensino público, a importância do discurso liberal e a crítica das constantes sociais e das variações culturais verificadas na dinâmica da sociedade brasileira.

\section{A REINVENÇÃO DA EDUCAÇÃO NO IMPÉRIO}

Sob o nome de educação popular, Rui Barbosa - que não foi educador de ofício, jamais exerceu o magistério, não desempenhou cargos de administração e também não foi inspetor de ensino ou diretor de escola - pretendeu combater aquilo que identificava como a chave misteriosa das desgraças que atingiam o Se- 
gundo Império: "a ignorância popular, mãe da servilidade e da miséria". Sua ambição era garantir a existência constitucional e a liberdade da nação. Sob muitos aspectos, tornou-se uma referência obrigatória nos estudos brasileiros sobre a instrução pública, pois, ao situar a educação popular no centro de suas preocupações políticas, Rui trilhou um caminho fundamental para o projeto liberal de uma abrangente transformação da sociedade brasileira. "Todas as leis protetoras são ineficazes, para gerar a grandeza econômica do país; todos os melhoramentos materiais são incapazes de determinar a riqueza, se não partirem da educação popular, a mais criadora de todas as forças econômicas, a mais fecunda de todas as medidas financeiras" (Barbosa, 1946, v. 10, t. I, p. I43).

A questão é que o potencial para uma estreita relação entre a ação estatal e a expansão da educação na sociedade brasileira dependeria de um sistema de ensino em que a instrução pública fosse controlada por órgãos governamentais especializados. Se essa idéia não resultou numa vitória nítida num primeiro momento, repercutiu nos escritos de educadores influentes na consolidação de um novo ideário educacional nos anos de 1930. Em A pedagogía de Rui, Lourenço Filho descreve o que se passou logo no início da formação do Estado Novo do seguinte modo:

Com o princípio da centralização, e até como seu regulador, Rui defende a necessidade de que todo o sistema seja fundamentado em bases objetivas. Ninguém mais do que ele pregou a necessidade da estatística escolar, sistematizada por órgãos do governo central, idéia que só 50 anos depois, no entanto, seria concretizada, em nosso país, graças aos esforços de M. A. Teixeira de Freitas e que, enfim, havia de tornar-se conquista definitiva, com o Instituto Brasileiro de Geografia e Estatística esplêndida realização do patriotismo do Embaixador José Carlos de Macedo Soares. (Lourenço Filho, 1954, p.29)

Esse entendimento foi estabelecido, sob diferentes estratégias narrativas, também nas obras de Fernando de Azevedo e Almeida Jr., sob a grave pena de perpetrar uma miopia, que apagando o funcionamento e a evolução da instrução pública durante o Império, inevitavelmente obscureceu e mistificou um período fundamental na sistematização da educação popular no Brasil. Nesse caso, não só é ressaltada a inexistência ou a falta de organização das instituições educativas mas, também, são muito utilizadas as figuras da precariedade: a palmatória, o analfabetismo generalizado, as classes fantasmas, os professores improvisados; figuras que povoaram durante muito tempo a representação histórica a respeito 
da educação no Império e na transição do Império para a República (Vidal, Souza, 1999, p.7).

Recentemente, a historiografia da educação tem problematizado essa representação. Suas contribuições para compreender como a escola elementar foi, nesse período, constituindo sua representação de local especificamente destinado ao cuidado da infância têm distinguido da organização e funcionamento das instituições de instrução imperiais uma arquitetura de normas e fazeres fecundos. É o caso, por exemplo, das pesquisas sobre as fontes da instrução pública paulista e carioca, produzidas no âmbito do Centro de Memória da Faculdade de Educação da Universidade de São Paulo², e as análises sobre a configuração da historiografia da educação elaboradas a partir do programa de pós-graduação da Pontifícia Universidade Católica de São Paulo ${ }^{3}$. Os estudos publicados por meio desses núcleos fazem uma nova abordagem do período, atenta não só aos agentes, às instituições e aos processos de formação e ensino mas, sobretudo, às diversas narrativas responsáveis pela descrição do processo de substituição das variadas formas de educação pela formação escolar, isto é, da própria institucionalização de um modelo oficial de educação.

Essas investigações são realizadas em torno de questões que têm sido há tempo objeto de estudo (escolas de ensino mútuo, professores de ensino elementar, ensino secundário e profissional, escolas normais, as idéias que circulavam, as escolas confessionais, a história administrativa). Em contrapartida, constituem um domínio sobre os procedimentos narrativos mobilizados na construção do conhecimento acerca da história da educação anterior ao período republicano. Como resultado, emergem novos significados relativos à conformação da cultura escolar durante a transição do Império para a República pela pesquisa sistemática: agora, não somente o discurso oficial, mas, sobretudo, a rede escolar, os atores, os conteúdos, as práticas do ensino e o cotidiano escolar oferecem os faits divers reclamados pela problematização das múltiplas práticas sociais, educacionais e pedagógicas desses anos (Hilsdorf, 200 I, p.69).

Nessa outra configuração da educação no Oitocentos, a interpretação de Rui Barbosa acerca da educação de seu tempo é decisiva para identificar toda a

I Trata-se principalmente dos trabalhos publicados tendo como objetivo levantar e compreender as fontes provenientes do movimento de educação realizado no Oitocentos. Ver sobretudo o trabalho: Vidal, Souza, 1999.

2 São principalmente os estudos elaborados para compreender e mapear a produção historiográfica a respeito da história da educação brasileira. Tem-se uma boa amostragem dos resultados desse esforço nas pesquisas publicadas por Bomtempi Júnior, 1995 e Warde, Carvalho, 2000. 
série de disposições políticas mobilizada pelo gesto de escolarização. Ela inicia com o esforço de objetivação da fragilidade desse movimento no Brasil daquele período. Assinala o fracasso da escola, a inépcia dos mestres e a ineficiência da instrução pública imperial. É, segundo a leitura de Maria Helena Patto (1990), um dos primeiros documentos que se ocuparam da produção do fracasso escolar. Sob essa rubrica, Rui Barbosa sublinha no seu exame:

Salvo as diferenças pessoais de inteligência e instrução de alguns professores, em quem, seja como for, o talento e o estudo não podem suprir a mingua de preparação pedagógica, impossível nos estabelecimentos que entre nós assoalham o título de escolas normais e que no geral não são senão normas pretensiosas da antiga rotina - o que se asila sob o teto desses edifícios opulentos é, nem mais nem menos, a velha tradição dos obsoletos processos de cultura humana, cujos resultados em toda parte sempre foram a caquexia geral das inteligências e o entibiamento das qualidades morais entre as gerações nascentes. (1946, v. I0, t. I , p.79)

As dificuldades para escolarizar a população brasileira são todas atribuídas ao governo central. O que está em questão nos Pareceres é o problemático papel do Estado diante desse processo. E como Rui Barbosa abordou nada menos que todo o sistema de instrução monárquico, pode-se dizer que a sua questão é a da própria organização nacional do ensino. As relações entre Estado e escolarização são objeto da publicidade política: para Rui Barbosa o poder público não pode declinar da tarefa de estender a cultura e a educação, protegendo os cidadãos contra a ignorância. É com esse ponto de vista que trabalha por uma concepção de educação adequada à população, profusamente dotada nos orçamentos e adaptada a todos os gêneros de cultivo da inteligência humana (Barbosa, 1946). Nesse aspecto, ao propor a cultura intensiva e extensiva do espírito popular mediante a mais sólida e completa organização de ensino, Rui Barbosa tenta acompanhar não só a difusão dessa idéia pelo mundo, como também a sua implementação administrativa. Não obstante, a morfologia da organização pedagógica é o traço mais forte da reforma planejada nos Pareceres.

A sua percepção da estrutura pedagógica da instrução pública, mais do que sistemática, é a de uma estratégia de formação cultural e moral: uma profunda convicção acerca da necessidade de associação entre a instrução popular e o cultivo moral (idem). Em parte, predomina nas considerações a esse respeito a preocupação com o tempo das lições e os espaços de ensino, o limite de alunos convenientemente reunidos numa classe, sua higiene, a co-educação, a formação do profes- 
sorado e a extensão dos estudos primários. Em contrapartida, a ênfase sobre a necessidade de consolidar a associação da instrução com a formaçãa moral constitui um meio de advogar para a educação popular uma via segura para realizá-la: concentra-se sobre os métodos de ensino, os programas escolares e a estruturação institucional. São três dimensões de uma só tentativa de explicitar a capacidade de homogeneização cultural e de ação moralizadora de um sistema nacional de educação orientado para estabelecer parâmetros para a cidadania e para a organização social do trabalho. Essa convicção que acompanha os Pareceres formaliza três concepções fundamentais acerca da educação popular no período. Primeiro, ela oferece canais adequados de aculturação numa sociedade vista como incapaz de melhorar por si mesma ou mesmo de entender como seria essa melhoria. Segundo, deve ser uma atividade racional, afinada com os princípios da ciência moderna e, de modo mais geral, com os preceitos da civilização. Finalmente, representa a oferta liberal de emancipação social para as classes estigmatizadas como inferiores, é o recurso oferecido a qualquer indivíduo para o autocultivo, a automelhoria ou o selfgovernment.

Tudo isso já é conhecido. Trabalhos publicados recentemente como os de Vera Teresa Valdemarim Gonçalves (1994) e de Terezinha Quaiotti do Nascimento ( 1997 ) abordam o tema. Contudo, por trás dessa proclamação parlamentar em torno do duplo discurso da emancipação e da coerção moral instituída, mediante o qual se definiu a conveniência da educação popular então proposta, está a crítica elaborada nos Pareceres sobre a organização escolar do Segundo Império. Rui Barbosa elaborou um discurso político-educacional repleto de referências, símbolos e estereótipos. Nesse sentido, a reforma evocada para transformar o estado da cultura nacional referia-se, na prática, mais à educação das classes trabalhadoras que, ao conjunto da sociedade, reivindicava uma ação corretiva da instrução pública contra a indigência e a criminalidade, baseada numa adequação de recursos culturais às exigências de situações concretas. Isto é, o discurso responsável pelos vínculos da educação com a ordem social e o progresso econômico, muito sedimentado na Europa e nos Estados Unidos, encontrou um lugar privilegiado também no território brasileiro, fixando em um estado de precariedade o sistema de ensino instalado. Rui Barbosa foi ainda mais longe: mostra a instrução popular como um campo estratégico para avaliar as possibilidades do jogo político. A compilação de extenso material sobre a importância do ensino popular para a sobrevivência das nações serviu para isso. De Washington a Comte, a mesma corrente de argumentos é aproveitada. Segundo Rui Barbosa, a educação popular resulta não só em renovação das formas 
de produção como também é o principal elemento da força e da estrutura de um Estado; educação popular e autoridade pública pertencem ao mesmo debate: "Felizmente, não é privilégio das repúblicas a percepção dessa dependência inviolável entre a educação do povo e a vitalidade das instituições. As monarquias esclarecidas, previdentes, moralizadas, dignas de viver, têm percebido com a mais perfeita penetração este requisito fundamental da ordem e do progresso" (Barbosa, 1946 , v. I0, t. I, p. I32).

Por meio dos índices de escolaridade da população, apresentados no primeiro capítulo do tomo I dos Pareceres, Rui Barbosa registra a escassez de agentes sociais privilegiados formadores da nação. A involução aí notada atesta não só a precariedade da expansão do ensino oficial mas a ilusão de sua eficiência, isto é, a despeito do aumento do número absoluto dos índices de escolarização (matrícula e freqüência) o sistema de ensino era identificado como irrelevante para a ascensão econômica ou para a transformação social. Ela significa também uma ameaça à existência constitucional do país. A "insigne deseducação do povo" é denunciada como fonte da legitimidade política de governos incapazes. A incompreensão da lei e a ignorância dos deveres cívicos, daí resultante, congestionam e enrijecem os componentes políticos da ordem social e do progresso econômico, segundo a compreensão do próprio Rui Barbosa. Nesse sentido, é a própria autoridade pública da monarquia que ampara a discussão elaborada nos Pareceres. Assim, o que Rui Barbosa diz nos Pareceres vai um pouco além da preocupação com a formação e expansão de um sistema público de educação popular e a necessária atualização das tecnologias de controle da demanda escolar. Mais que a institucionalização de formas eficientes de transmissão cultural na órbita do Estado, é assunto dos Pareceres a permanente revitalização da governabilidade do país.

Essa mesma consciência e interpretação das relações entre educação popular e autoridade pública esteve também presente no entendimento de outras elites do país. Em São Paulo, o grupo ao qual João Köpke ligou-se profissional e politicamente partilha os mesmos princípios educativos fundamentais de Rui Barbosa: ensino intuitivo e concreto. As mesmas referências relativamente ao ensino popular, encontradas nos Pareceres, ordenam aquilo que as elites progressistas paulistas consideravam necessário para a formação do espírito e do caráter do cidadão: uma organização pedagógica capaz de oferecer uma formação moral, a crença no poder educativo das ciências, a consolidação de um padrão cultural modelado no domínio da prática e uma perspectiva ocupacional oferecida àqueles que se destinavam aos trabalhos manuais. São princípios e referências também centrais na organização das propostas de 
João Köpke para a reforma da instrução pública da Província do Paraná e para a reorganização do sistema de educação do Distrito Federal após a mudança de regime. Existe, antes de mais nada, essa preocupação de situar a educação da população no interior de uma estrutura de ensino simultaneamente "útil" e "científica". A instrução pública é vista, em ambos os casos, como elemento importante para o desenvolvimento da inteligência nacional. Nesse sentido, a sua sistematização tem a ver com a própria capacidade do serviço público para instituir essa função capital na escola.

\section{ESTADO EDUCADOR E AMBIGÜIDADES DO LIBERALISMO SOBRE A OBRIGATORIEDADE DO ENSINO}

Tanto o projeto de reorganização elaborado por João Köpke, a pedido do ministro do interior, quanto a proposta de reforma, encaminhada ao governador da Província do Paraná pela comissão diretora do Colégio Neutralidade, apresentam simultaneamente cumplicidade e hostilidade em relação aos Pareceres na maneira de compreender questões de ensino relativas à educação das crianças que freqüentavam as escolas públicas do país. Essa situação é muito reveladora das ambigüidades do liberalismo brasileiro no último quartel do século XIX. Fundamentalmente educador, João Köpke expõe nesses documentos as diretrizes e preocupações que os aparelhos públicos de ensino precisariam ter para realizar a instrução popular. São dois projetos de reforma de ensino público, mas em ambos os projetos saltam aos olhos os motivos políticos, um certo número de juízos e sobretudo alusões maliciosas: "Para empreender a reforma do ensino público é necessário que nos coloquemos num ponto de vista despeado de todas as sutilezas metafísicas que a falsa orientação mental dos legisladores tem tomado para norma de suas criações" (Köpke, I889, fl. I).

João Köpke identifica no legislativo os inconvenientes políticos da estatização da instrução pública sem apresentar qualquer das suas vantagens práticas. Para ele, contrariamente ao que pensa Rui Barbosa, o legislativo não é, na verdade, a garantia constitucional do direito à educação, da qual dependia a instrução pública, mas a garantia da extraordinária minúcia governamental na regulamentação de seu funcionamento. Assim, é levado a sobrestimar, no seu conjunto, a capacidade administrativa do poder executivo. $\bigcirc$ âmago do seu pensamento está resumido na passagem final da justificativa, apresentada ao projeto de reforma do ensino no Distrito Federal, em dezembro de 1889, que define a educação popular como "a sombra das instituições republicanas". 
Ainda, no entender de João Köpke:

... a instrução popular, antes de tudo deve ser: - positiva, conforme o espírito da nossa época, adaptada as necessidades da civilização moderna e oferecendo variedades de extensão em um sistema constantemente semelhante e idêntico; isto é, abranger todos os conhecimentos humanos nos seus princípios cardeais, de maneira que se torne praticamente eficaz para de tal arte, cada um na esfera da sua posição, utilizá-la no desempenho geral de suas funções sociais, em atenção as especializações técnicas, dependentes de capacidades oficialmente reconhecidas e privilegiadas. $(\mid 889$, fl.5)

Esta convicção conduz João Köpke a sistematizações doutrinárias a propósito dos modos de viabilização desse tipo de instrução. $\bigcirc$ argumento central organizado no projeto de reforma é fiel à tese liberal da intervenção estatal mínima:

O Estado não pode obrigar o cidadão a instruir-se: $1^{\circ}$ porque, ex vidas condições da população, principalmente em nosso país, o preceito não pode ser geral, e os excetuados hão de ser mais numerosos do que os sujeitos a regra, pelo que a tolerância das recepções prova que se a ignorância é uma desvantagem, não é um mal [...]; $2^{\circ}$ porque é uma coação à liberdade não exigida pelo interesse comum, pois não esta provado, nem podem nunca provar-se que a escola da virtude ou do crime suba ou baixe na proporção da instrução popular. (Köpke, | 889, fl.7)

Esta opção política tem para Köpke a vantagem de evitar tanto a iniqüidade de obrigar a receber o que dificilmente e mal se poderia dar quanto uma coação à liberdade individual. Mas a dificuldade está em rebater o argumento em que se assenta a obrigação escolar: na gratuidade do ensino, no direito do cidadão à instrução, no direito que o Estado tem de instruir pois a ele cabe a punição do crime e, portanto, é ele o testemunho da estatística do crime. Todas essas quatro grandes linhas de argumentação estiveram presentes antes nos Pareceres. Desse modo, existe, no interior da problemática, um itinerário comum para Rui Barbosa e João Köpke. Porque a compreensão do significado da obrigatoriedade escolar para as responsabilidades políticas do poder público é a mesma para ambos os proponentes: é a das relações entre a sociedade civil e as instituições públicas, entre o Estado social e o governo.

Mas para Rui Barbosa, ao contrário do que fazem entender as considerações de Köpke, somente com a adoção da obrigatoriedade escolar se poderia assegurar 
tanto a cabal harmonia com o intuito que inspira o Estado perante a situação da educação popular, quanto a satisfação integral das exigências fundamentais que legitima sua ação (Barbosa, 1946). A gratuidade e a obrigatoriedade do ensino elementar foram vistas por Rui Barbosa como associadas para que fosse assegurada a plenitude dos direitos que as determinam e que são fundamentalmente dois:

- o direito irrecusável a toda criatura humana, de que a sociedade the subministre, no primeiro período da evolução individual, os princípios elementares de moralidade e intelectualidade;

- o direito de negar à ignorância do indivíduo a liberdade de obrigar a nação a receber, no seio da ordem comum, cérebros atrofiados pela ausência dessa educação rudimentar. (idem, v. I0, t. I, p. 183)

As reflexões de João Köpke sobre a associação entre obrigatoriedade e gratuidade do ensino são de outra natureza:

Se o cidadão tem direito a instruir-se, a sociedade tem o dever de lhe proporcionar instrução, como ele tem direito a sua propriedade e vida, a sociedade tem o dever de lhas assegurar. Ora se ninguém jamais sustentou que a polícia é gratuita, ninguém jamais sustentará que o é a escola, porque uma e outra são sustentadas pelo orçamento que é a soma das contribuições de todos para custear as despesas em vantagem da comunhão. (Köpke, |889, fl.7)

O direito à instrução demarcava, para Köpke, a educação como área social, cuja participação começaria pela contribuição ao orçamento. Assim, se por um lado preservava a obrigação do Estado de oferecer instituições de ensino para a sociedade, por outro, reconhecia o papel que caberia à sociedade na constituição desses estabelecimentos. Na verdade, legitimava a defasagem de vagas nas instituições públicas de ensino em relação à população em idade escolar, pela responsabilidade que colocava sobre a sociedade no custeio das "despesas em vantagem da comunhão". Na mesma proporção que desarmava a justificativa da obrigatoriedade pela gratuidade mediante as implicações legais que seu conceito carregava, desarticulava a noção que associava a necessidade da educação ao direito que tinha o cidadão à instrução, uma vez que contribuía para seu custeio. Dizia ele: "É condição do direito ser facultativo o seu exercício. Direito obrigatório é dever. Se a instrução, pois, é um direito, não pode ser obrigatória" (idem, ibidem). Essa forma de compreender 
a questão deixa livre de penalidade legal aquele que se recusa a exercer aquilo que the é de direito.

Perante a questão, Rui Barbosa (1946) foi taxativo: "não há possibilidade de instrução popular sem a sanção da coercitividade legal”. A contradição fundamental na interpretação diz respeito ao papel do Estado na organização da instrução pública, e à noção de justiça de que é investida a sua ação. Os Pareceres fazem ressaltar uma relação necessária entre o grau de difusão de cultura e a imposição da lei, a imposição do código penal e a imposição da escola na manutenção da ordem social. Nesta aproximação, obrigar à instrução significava preparar a inteligência e os sentimentos do povo para "avaliar a perniciosidade da infração, perceber a inferioridade moral que ela denuncia no delinqüente e adquirir horror ao estigma que a lei inflige ao condenado" (Barbosa, 1946). Segundo esse entendimento, é uma função do Estado obrigar à instrução elementar onde impõe o código penal.

É diferente o significado atribuído por João Köpke. $\bigcirc$ direito de instruir que o Estado que pune poderia ter é refutado no que diz respeito à extensão de sua ação nos seguintes moldes: "Se o Estado tem o direito de instruir, porque tem o direito de punir, não tem o direito de excetuar ninguém da instrução, e onde exista um cidadão que não instruiu, há de levantar uma escola, ou há de suspender a ação do código penal, fechando a cadeia e banindo o juiz" (Köpke, I889, fl.8).

João Köpke não tem a preocupação de discutir a obrigatoriedade do ensino do ponto de vista das vantagens que tal medida ofereceria ao progresso do país ou à extensão da cidadania; detém sua atenção na tarefa de explicitar de modo nítido o alcance que deveria ter a ação estatal nos negócios individuais. No fundo, a livre iniciativa é preservada da intervenção oficial, pois, como advertia a comissão do Colégio Neutralidade ao governador da Província do Paraná quatro anos antes, é de bom tino político e alta moralidade suprimir uma coação que desnobilita os esforços do país e dos cidadãos. Nesse sentido, a função do poder público nos domínios da educação popular fica limitado a "dar livremente, sem a menor obrigatoriedade, uma coisa que todo o homem moderno quer, e que quando não quer é porque não pode - a instrução" (Köpke et al., 1940, p.397).

Finalmente, se para Rui Barbosa (1946) parecia cientificamente demonstrado que o grau de difusão da instrução estava diretamente relacionado à criminalidade, João Köpke considera, pelo contrário, as relações entre instrução e criminalidade um equívoco estatístico. Ele evoca o testemunho da estatística tão-somente para denunciar que a procura de uma relação necessária e matemática entre esses dois termos revelaria o desconhecimento de que, ao mesmo tempo em que se 
desenvolve a instrução, a ação das leis e a organização da polícia também haveriam de influir nos resultados considerados (Köpke, | 889, fl.6). Köpke insiste no fato de que se a ignorância é uma desvantagem, não é um mal, e enumera os motivos com base nos índices estatísticos: o que decresce numa comparação entre instrução e segurança pública não são os crimes mais graves; que os crimes contra a vida das crianças e os atentados ao pudor aumentam, que avultam os delitos, que os roubos simples e as ofensas físicas aumentam com a riqueza, que os homens delinqüem mais que as mulheres, os celibatários mais que os casados e que os vagabundos fazem mais contigente nos tribunais (idem, fl.7).

Essas diferenciações regulam, coordenam e legitimam oposições políticas fundamentais. Indicam a especificidade da influência social da instrução pública sobre o interesse particular quanto ao alcance da idéia de direito comum em cada um dos autores. Köpke ignora as conseqüências políticas do estado de organização da instrução pública: vê o desejo de aprender e se desenvolver como um sentimento inato nos homens que, liberados pela legislação, buscariam os locais adequados para tal empreendimento. Para Rui Barbosa, em vez disso, faz-se necessário assegurar a ação do Estado nesse aspecto da vida social, a fim de preservar o arbítrio em favor do bem comum. Radical, portanto, a oposição entre os liberalismos de um e de outro. João Köpke admitia a possibilidade de uma elaboração autônoma do sistema de ensino, isto é, sem alargamento da ação do Estado e, em parte, também tarefa da iniciativa privada. A liberdade de ensino era, nesse caso, determinante para atingir grandes resultados no tocante a disseminação da instrução. Rui Barbosa desconfiava dessa possibilidade. Reconhecia na liberdade de ensino uma garantia contra a intervenção estatal na escola particular, autonomia pela qual preservava o Estado do encargo de uma fiança que não encontraria meios para honrar naquele momento: o ensino com diploma oficial de capacidade. Mas desconfiava, no entanto, que, como propulsor da educação popular, o Estado pudesse ser substituído pela iniciativa particular:

Enquanto a preocupação de alguns sistemáticos e o exclusivismo de certos teoricistas [...] encarecem a iniciativa individual como capaz de substituir o poder público no seu papel atual de grande propulsor da educação popular e da alta cultura científica [...] a tendência universal dos fatos, na mais perfeita antítese com essas pretensões, com o subjetivismo das teorias dessa nova classe de doutrinários, reforça, e amplia, entre os povos mais individualistas, com o assentimento caloroso dos publicistas mais liberais, o círculo das instituições ensinantes alimentadas pelo erário geral. (Barbosa, 1946, v. 10 t. I, p.85-86) 
A distância das duas posições confere realidade política ao uso das idéias liberais no encadeamento de um programa de sistematização da educação pública. ○ caráter dessa realidade e dessa distância, foi percebido pela historiografia da educação em circunstâncias de confronto direto. É na comparação entre o Decreto n. 7.247 de 19 de abril de 1879 e o estudo dele resultante, justamente os Pareceres de 1882, que as reflexões de Vera Valdemarim Gonçalves (1994), por exemplo, pontuam as diferenças, produzidas pelos liberais do período, na leitura do estado da educação brasileira e no projeto para sua reforma. Essas diferenças têm sido também apontadas em outras pesquisas acerca das reformas da instrução pública entre 1890 e 1920 como as que abordam a influência do programa do partido republicano na organização do ensino no Estado de São Paulo (Reis Filho, 1995). A análise que Jamil Cury faz da Constituinte de I89| na sua tese de livre docência, recentemente publicada, sublinha ainda uma vez o antagonismo característico da política dos liberais no campo da educação:

A educação do ponto de vista administrativo, ficou aberta tanto à iniciativa estatal quanto à iniciativa privada. Os liberais por ideologia ou pragmatismo, não poderiam se fechar a nenhuma das iniciativas. Pelo lado estatal, a educação pública era vista como instrumento de oportunidade no acesso aos direitos políticos, mas sem coação e pelo lado privado era vista como uma questão de escolha e concorrência. (Cury, 1991, p.382)

No conjunto, o quadro apresentado por essas pesquisas indica momentos importantes de disputa entre esses dois liberalismos na conquista das casas legislativas. Em 1879, a comissão de instrução responsável pelos Pareceres que Rui Barbosa redigiu responde às formalizações do Decreto n.7.247 acerca da liberdade de ensino com restrições importantes às liberdades individuais de pensamento e ação, tais como a obrigatoriedade escolar e a centralização do controle institucional dos estabelecimentos de ensino por parte do Estado (Gonçalves, 1994, p.34). Em São Paulo, as primeiras décadas republicanas assistiram à substituição de formas de intervenção do Estado na criação e manutenção das escolas organizadas por Caetano de Campos (na direção da Escola Normal entre 1890 e 189|), Gabriel Prestes (com o projeto substitutivo de Reforma da Instrução Pública, aprovado em 17 de agosto de 1892) e Cesário Motta Jr. (como Secretário do Interior entre 1893 e 1896) pela estruturação do ensino público mediante outra sistemática administrativa. De feição autoritária, as reformas posteriores orientam um processo de concentração 
de poderes nos órgãos superiores da administração pública em que desaparece a repartição colegiada da instrução (o Conselho Superior); cedem também às influências político-partidárias da oligarquia paulista (Reis Filho, 1995, p.31). Finalmente, em I891, a Constituinte produz um afunilamernto das pretensões liberais perante o conservadorismo das elites políticas até reduzir a educação e a cidadania à alfabetização e ao voto, respectivamente. A gratuidade e a obrigatoriedade seriam aceitas nos limites da organização federativa que abria espaços para as constituintes estaduais legislarem sobre o assunto. A República procurou na descentralização os caminhos da cidadania, fez com que o ensino oficial não fosse reduzido a um capítulo do ensino livre, porém, não resolveu suas prerrogativas de autonomia orçamentária (Cury, 1995, p.383-384).

○ quadro certamente ultrapassa o interesse pela descrição histórica desses confrontos. Os problemas presentes nas discussões de |879, |89| e nas reformas do sistema de ensino público paulista entre 1890 e 1920 estão latentes nas preocupações políticas da prática educativa. E nesse caso os programas de reforma da instrução pública de Rui Barbosa e João Köpke são a conseqüência de um impasse nas posições liberais. Havia uma variedade de respostas aos problemas da difusão da instrução na sociedade brasileira mas não trouxeram solução para ele. A universalização de certas oportunidades educacionais, a transformação das técnicas e dos métodos pedagógicos ou ainda a interação aberta e construtiva do ensino com as necessidades e os interesses da sociedade em que ele era praticado foram plataformas igualmente incapazes de consolidar uma política de educação duradoura. Pode-se dizer que em todas elas o nexo entre educação e cidadania foi central para justificar a necessidade de expandir uma rede de instituições escolares estruturada e sistemática.

Dentro do esquema geral do liberalismo das elites progressistas nacionais, traçado por Roque Spencer Maciel de Barros (1959), esse nexo distinguia duas opções: uma visão jurídica do homem que partia da crença fundamental na liberdade humana, cujo núcleo devia ser constituído por meio do sistema educacional, da mentalidade dominante nas relações pedagógicas e dos produtos dos processos educativos. Em oposição, uma interpretação cientificista ou pretensamente científica da educação, visando à reconversão qualitativa do padrão organizacional da rede de ensino instalada. A primeira, aproxima o liberalismo do Estado, aceita a atividade do Estado, compreendendo que o particular não podia arcar com as necessidades da educação em geral e que, se o fizesse, seria duvidoso que seu objetivo fosse simplesmente o de propagar a instrução. $O$ preço dessa aproximação por mais relativa que 
ela fosse, era o exame do problema do Estado-Educador. Poucos liberais deste período desejaram que o Estado apoiasse doutrinas, impusesse idéias, a maior parte deles defendeu, em vez disso, que o Estado velasse pelo nível de ensino oferecendo o máximo de seus recursos à educação, o que esteve fora do círculo dos interesses da iniciativa particular. João Alfredo, em projeto apresentado à Câmara em 1874, e Tavares Bastos, nas páginas de $A$ Província de São Paulo, foram exemplos dessa opção.

A alternativa era procurar reduzir ao mínimo a ação do Estado, a fim de libertar a educação do artificialismo das imposições constitucionais, para submetê-la apenas a sua evolução natural e às legítimas injunções coletivas. Neste caso o programa político-social foi outro: deixar de lado o caráter utópico da obrigatoriedade, antes que fossem criadas as condições econômicas e sociais que permitissem a sua efetivação. Pereira Barreto, Teixeira Mendes e Tobias Barreto representaram essa opção: lembravam, em seus escritos e pronunciamentos, que uma instrução primária reduzida à leitura, à escrita e ao cálculo aritmético eram somente um meio de aquisição da instrução verdadeira e que se a alfabetização fosse condição necessária, mas não suficiente para formar o cidadão, não deveria nem mesmo ser iniciada. Viam na obrigatoriedade uma violação da liberdade espiritual, um produto da crença segundo a qual o grau de progresso e de civilização de um país se mede pela instrução do povo, quando o correto, pensavam, era a educação esse propulsor.

\section{POLÍTICA DE EDUCAÇÃO E CONSEQÜÊNCIAS CULTURAIS DA ESCOLARIZAÇÃO}

A tentativa de superar esse impasse introduziu o tema da educação nas áreas mais fundamentais para a ordem escravocrata e senhorial do império, quais sejam: o exame das leis do funcionamento econômico, a análise da máquina política de Estado e as estratégias de distinção social utilizadas pelo indivíduo para incorporarse a ela. Os Pareceres talvez tenham sido a primeira expressão articulada desse esforço a partir dos problemas educacionais em direção às questões político-sociais mais gerais; as propostas de reforma de João Köpke foram representativas dele. $\bigcirc$ resultado em ambos os casos foi o mesmo: uma proposta de estruturação do ensino público tendo em vista as conseqüências culturais da escolarização em massa.

Nos Pareceres, Rui Barbosa estabeleceu o elo fundamental entre a educação das classes populares e a diferenciação social. Em padrões de controle e disciplina, esta é a racionalização crucial a ser institucionalizada. Assim Rui Barbosa pergunta: "Tereis educado as classes populares, as camadas operárias e as partes menos 
afortunadas e mais duramente laboriosas da nação, se não lhes incutirdes, pela evidência das leis naturais, a convicção do caráter providencial das desigualdades, em que a riqueza divide os homens ainda nos Estados mais felizes?" (1946, v. I0, t.2, p.361).

Esse espectro do conservadorismo social e político do liberalismo das elites brasileiras talvez seja o elemento mais crucial das sistematizações da educação popular elaboradas em fins do Oitocentos. Também Köpke o alimenta quando nega, nas atribuições do pátrio poder, a paridade entre o dever da subsistência material e intelectual:

... a necessidade daquele começa com a vida; a desta não; - a fome mata fisicamente; a ignorância nem física nem moralmente mata. $\bigcirc$ faminto é um moribundo; o ignorante pode ser um ente capaz de colaborar com eficácia para prosperidade de uma comunhão; como o atesta entre nós, o elemento africano, intervindo em todos os estádios de nosso desenvolvimento com as qualidades preciosas da raça afetiva que personifica e que fora lacuna obscurecer. (Köpke, I889, fl.5)

Nestas circunstâncias, as propostas de reforma do ensino público propõem uma estrutura escolar de caráter moralizador e disciplinar cujas finalidades eram inspirar o amor ao trabalho e à pátria. Fornecem um diagnóstico que justifica a caracterização do processo de aprendizagem como aquisição experimental de uma educação enciclopédica e humana: a necessidade de difundir nas classes populares um conhecimento utilitário e prático. Estava aí uma resposta estrutural à constituição e expansão de um sistema de ensino popular. Inequivocamente, o ensino primário e o profissional destinavam-se ao povo e deveriam desenvolver currículos para habilitar ao trabalho. Os trabalhos manuais eram, sem dúvida, exclusivo deles e, na avaliação de João Köpke, o melhor meio de povoar as escolas. Para Rui Barbosa explicitavam a orientação prática do programa escolar. É o mesmo papel que cumprem o ensino do desenho e do canto na educação popular. Na escola primária esses conhecimentos seriam transmitidos segundo uma orientação prática. $\bigcirc$ desenho, para o fomento da indústria, e a música, como instrumento para adoçar as classes populares, eram considerados fortes auxiliares da cultura moral e importantes instrumentos de aperfeiçoamento do conjunto da inteligência, da leitura e da escrita.

Esse conjunto comum de respostas de Rui Barbosa e João Köpke para o desenvolvimento de escolas populares obedecia estratégias de realização distintas.

Rui Barbosa insistiu na regulamentação oficial de uma nova estrutura. Classificando a escolarização primária em três graus, de acordo com o tempo despendido 
na escola, os Pareceres reivindicavam quatro anos de escola primária superior, subseqüentes a dois anos de escola primária média e a outros dois de escola primária elementar.

Destarte, sendo de sete anos, a idade inicial da escola, aos quinze se completaria a educação comum dos que não se voltarem a carreiras profissionais.

Os que houverem de encetar a preparação para estas, deixarão a escola no nível médio, termo onde remata o período obrigatório de instrução, e irão receber, nos cursos técnicos, ou nos institutos de ensino secundário [...], a instrução nos estudos que a escola superior ministra em esfera mais limitada e comum, nas suas aplicações, a todas as carreiras. (1946, v. 10, t.3, p.56)

Sendo essa a estrutura central do sistema público de ensino, os Pareceres previam ainda instituições para um período de educação preliminar à escola: os jardins-de-infância. Julgada por João Köpke como um atentado contra a moral social, um pietismo desorganizador, a educação pública infantil nos jardins-de-infância era para Rui Barbosa a promessa dos mais satisfatórios resultados:

Por ela se despertam, e enraízam os hábitos de regularidade, pontualidade, silêncio, docilidade, benevolência e polidez, se desenvolve a capacidade inventiva, se habitua à atenção laboriosa e à observação crítica, se adestra o espírito, como o corpo, em conceber, dizer, e fazer com firmeza de propósito, consciência do fim e escolha coerente dos meios. (idem, v. I0, t.4, p.87)

Segundo a estrutura proposta por Rui Barbosa nos Pareceres, à medida que se vai descendo os diversos níveis de escolarização é mais evidente que a sua função está implicada com a produção de uma disciplina do trabalho aliada à docilidade social.

João Köpke, em contrapartida, nos documentos desse período, não avança para além das graduações já vinculadas ao sistema e estrutura de escolarização instalada. Preferiu lidar com o aperfeiçoamento institucional da rede de ensino. Em sua proposta de reforma da instrução pública para a Província do Paraná, aduziu medidas referentes à ação governamental sobre o magistério, às condições dessa classe e outras referentes ao ensino. Tais medidas são sistematizadas em dez propostas:

Primeira: exigir, não existindo escolas normais, em concursos para a admissão ao professorado, provas de capacidade intelectual, seguidas da regência das aulas, além de provas morais que não possam ser iludidas. Segunda: rodear os assim nomeados 
de garantias de estabilidade e independência, que permitam um livre exercício de sua função. Terceira: estabelecer uma inspeção rigorosa, em visita às escolas da província, fazendo por essa ocasião o respectivo inspetor conferências sobre o ensino, esclarecendo teórica e praticamente o professorado. Quarta: deixar a admissão dos compêndios a escolha dos professores, podendo, entretanto, o governo aconselhalos a fornecer os pedidos, sem caráter de obrigatoriedade. Quinta: modificar o horário consecutivo geralmente seguido, intercalando intervalos, recreios entre as lições, tão necessários ao desenvolvimento físico da criança, como ao descanso intelectual, preparador da assimilação de novos conhecimentos. Sexta: não admitir crianças à escola antes dos sete anos de idade, antes dos quais segundo as melhores opiniões médicas, o ensino perturba o desenvolvimento mental e tende a empecer o físico. Sétima: no ensino da língua materna banir a soletração e a silabação como ilógicas e deturpadoras da inteligência da criança e da boa leitura. Oitava: banir o ensino da gramática e mormente o compêndio respectivo na escola, como a sã razão o indica, e as nações cultas o vão realizando. Nona: instituir os belos exercícios de uma leitura expressiva, duplamente vantajosa pelo lado artístico e intelectual; os de declamação de trechos poéticos, de tanto valor moral; e os de composição que, únicas, preparam para um manejo escrito da língua. Décima: nos rudimentos matemáticos fazer prevalecer a parte prática, precisa às necessidades da vida sobre a meramente teórica, sem esquecer que essa disciplina é mesmo mais um meio lógico que científico, o qual o planejou quanto a escola primária o ensinante Condorcet. (Köpke et al., I 940, p. 325-326)

Essas propostas, apesar de excluírem algumas perspectivas regulamentares, certamente favoreciam o estreitamento da aliança entre um padrão organizacional para a educação das classes populares e as diretrizes positivas e práticas do ensino. Pretendendo a profissionalização do professorado, o reconhecimento oficial das qualidades próprias dessa classe como instrumento de inserção e desenvolvimento social, designando a escola primária como agente de educação e determinando as exigências específicas do regime de trabalho dessas instituições, João Köpke impôs como evidencia essa associação. Era prevista uma organização capaz de constituir um sistema de controle dos usos escolares dos saberes científicos, de definição da ação educativa e de desenvolvimento de uma aprendizagem edificada pela prática e experiência de seus profissionais. $\bigcirc$ compromisso da Proposta e do Projeto não é mais que uma ambição institucional de consolidar um sistema de valores para o funcionamento do aparelho público de ensino. 
Rui Barbosa pretendeu mais prevendo uma organização capaz de intervir nos conflitos produzidos pelas primeiras realizações da acumulação de capital no Brasil. Deste ponto de vista, a intenção política ou de reforma social pode ser considerada dominante nos Pareceres. A interpretação é útil na medida em que situa a educação popular dentro dos planos de revigoramento das instituições liberais propostas por Rui Barbosa. Obtém-se assim um produto definido, uma estrutura de ensino determinada por um plano de organização extenso e minucioso, uma filosofia fundamentalmente idealista, uma proposta de metodologia largamente baseada no evolucionismo de matriz spenceriana e uma tecnologia de ensino atenta aos processos intuitivos da experiência sensorial (Lourenço Filho, 1954, p.54-55). Segundo Rui Barbosa, tudo isso orientado para a realização de uma compensação simbólica para a violência policial, mobilizada numa eventual necessidade de repressão contra as loucuras socialistas:

Se quereis, pois, cimentar a ordem necessária das sociedades em bases estáveis, é na escola que as deveis lançar. É antes de experimentar as primeiras agruras, as primeiras feridas do combate pela existência, que o futuro trabalhador há de sentir, pela direção da cultura que receberam as suas faculdades nascentes, o valor supremo, a inviolabilidade absoluta dos interesses que prendem à distribuição das categorias sociais pela herança, pelo merecimento e pelo trabalho. (1946, v. I0, t.2, p.36 I)

É evidente que essas formas de coação conduzem a precauções sectárias e conservadoras pouco convenientes contra as classes populares. Mas parece ser essa mesma a sua função: substituir o julgamento de valor para o jogo social e político dos interesses, a finalidade para a causalidade, o argumento de autoridade para a discussão. Ambos os autores propuseram a estruturação do ensino público, cujos elementos e finalidades analisaram, a partir dessa preocupação contra a estranheza do fenômeno que constituía a escolarização do povo; porque toda a proposta verdadeiramente responsável de reforma da instrução tinha em conta a avaliação de suas conseqüências culturais, a rotura democrática das oportunidades de educação dentro do funcionamento político-econômico da sociedade brasileira. Deste ponto de vista, é ainda uma vez Rui Barbosa que vai intelectualmente mais longe, derrubando as dúvidas postas quanto à ação corretiva do "derramamento do ensino" contra a indigência e a criminalidade e mostrando que, longe de ser a agente de uma rotura radical, a educação popular consolidaria, de fato, o funcionamento institucional do Estado. Quanto a João Köpke, é o seu positivismo republicano que o liberta do idealismo metafísico em relação ao entendimento das funções do Estado- 
Educador: a instrução pública era uma prática do direito de educar que tem o Estado que pune, não o seu resultado.

\section{UTOPIA SOCIAL, PROJETO POLÍTICO E REFORMA EDUCACIONAL}

A organização do sistema de ensino e o take-off para a escolarização transcorreram no Brasil sem consubstanciar uma política pública de instrução capaz de liberalizar alguns dos elementos funcionais do aparelho de ensino oficial. Na realidade, de 1869 a I889, foram divulgados compêndios pedagógicos e escritos estudos legislativos que reivindicavam a estruturação da educação popular, ao mesmo tempo em que foram instaladas escolas e instituições diversas, consolidando uma primeira forma administrativa para ela. Aí os confrontos entre excelência e eqüidade ou exclusão e inclusão constituíram um espaço importante de manobra política. $\mathrm{Na}$ definição dos programas escolares e dos processos de aprendizagem, nas modalidades de avaliação dos alunos, nas estratégias de recrutamento e de formação dos professores e na própria conformação institucional da escola pública foi pouco significativo o alcance do conceito de cidadania para a expansão da rede oficial de ensino.

É certo que muito falta fazer na análise histórica dos fatores que restringiram, no nível político e social, os índices da escolarização no Brasil. É bem conhecida, graças às pesquisas de Barros (1959), Hilsdorf (1986) e Mattos (1987), a clivagem entre concepções distintas de sociedade, acompanhando essas discussões ainda no Oitocentos. Mas se sabe pouco sobre as estratégias de enfrentamento e superação do problema. São ainda menos conhecidas as formas de racionalidade educativa paralelas às políticas públicas de educação. É possível que parte importante dos mecanismos de ensino e dispositivos escolares criados fora dos canais oficiais da instrução tenha a ver com a progressiva universalização da escolarização primária.

Do mesmo modo, a formalização de um pensamento acerca da educação popular, sua estruturação em sistema público de ensino e ambigüidades são ainda pouco estudadas; o que é certo é que, entre o primeiro liberalismo dos anos da independência, avançando para o liberalismo conservador dos "saquaremas", até o liberalismo republicano, a instrução pública revelou novos modos e várias versões do processo da educação e da escolarização na sociedade.

De resto, meu objetivo neste trabalho foi destacar algumas diferenças entre as propostas de João Köpke e Rui Barbosa para a estruturação da educação pública no último quartel do século XIX. Sublinhei que nessas diferenças conviveram formas 
prévias de reprodução social e projetos de escolarização para as classes populares. Tanto os Pareceres quanto a Proposta e o Projeto definiam normas e critérios para alocação de recursos para a extensão da instrução pública cuidadosamente pautados pela defesa e promoção da ordem social. Dentro dessa perspectiva, procurei entender algo da extensão dos debates e conflitos que envolveram a sistematização da instrução pública. Em certo sentido, a promoção da idéia de obrigatoriedade escolar respondia pela educação popular, servia para determinar legalmente o alcance do ensino oficial e fazia concessões à ação do poder público na institucionalização do modelo escolar dessa educação. Por outro lado, na elaboração do aparelho público de instrução, o combate aos fundamentos políticos dessa idéia impôs uma resistência significativa ao progressivo avanço da escolaridade da população. Embora existisse um consenso de que a educação popular devesse ultrapassar as suas origens utilitárias e buscar status e recursos para uma educação sólida, experimental e rigorosa, havia também a consciência de que a sua realização ainda era vulnerável como provedora de conhecimentos e hábitos socialmente valorizados. Isso significa que os conflitos em torno da educação popular não ocorreram apenas sobre a organização social do conhecimento, mas também sobre os seus objetivos e potencialidades.

São essas as distinções que estabeleci entre os textos de Rui Barbosa e João Köpke sobre educação pública. Elas permitem indicar o modo pelo qual a mesma crença nos processos internos de escolarização formalizou diferentes modelos de interseção de disciplinas escolares, pedagogia, finanças, recursos, avaliação e educação. A descrição dessas diferenças conduz a pelo menos três conclusões gerais sobre a movimentação para dar à educação popular uma forma institucional reconhecidamente segura e sistemática.

A primeira conclusão é que a educação popular não constituía uma rotura radical nas formas de transmissão cultural, mas apenas indicava uma direção de mudança. Representava a busca por um ensino eficaz, pela prática mais bem-sucedida para a educação das camadas populares. Aí, as prioridades sociopolíticas e a discussão de ordem intelectual tornam-se decisivas. Elas fornecem uma série de entendimentos em relação a aspectos de controle e operação da escola e de procedimentos de sala de aula. Então a atenção se desvia dos parâmetros da prática, dos aspectos cotidianos da escolarização, da análise histórica de construção social dos programas escolares. Episódios de outros aspectos da vida social legitimam esse desvio: os problemas de reconstituição mediante registros escritos da luta política, subjacente à substituição das diversas formas de educação pela formaç̧ão escolar, fazem parte da história de como um determinado conjunto de objetivos foi estabelecido e inserido 
na montagem de um sistema de escolarização considerado "seguro". Por esse motivo, compreendi a luta política que se deu em torno dessa montagem como o centro das oposições entre as propostas de sistematização da instrução pública de Rui Barbosa e João Köpke. De certo modo, procurei localizar aí a mobilidade política das representações sociais geradas pelos liberais brasileiros no último quartel do século XIX e, na medida em que o fiz, notei uma série de interrogações difíceis para a efetivação dessas propostas numa reforma da instrução pública. Que categorias sociais era preciso isolar umas das outras? Inversamente, que estratos sociais era preciso integrar? Que tipo e critério de escola seria necessário adotar, para isolar ou integrar convenientemente? Que sistema de relações (hierarquia, autonomia, estratificação) deveria ser inscrito entre esses estratos ou categorias sociais?

Em segundo lugar, a escola popular pode ser considerada uma idéia que se tornou realidade durante o século XIX, uma entidade que possuía forma institucional e forma técnica. As propostas das reformas da instrução pública buscavam contrabalançar o desencanto cada vez maior com o lugar ocupado por essas formas no cotidiano social e cultural da época. Considerando essas formas, cada uma por si, tem-se: a forma institucional indica que a escola primária era o professor, estava identificada à sua cátedra e dependia da organização que este pudesse dar ao ambiente em que ensinava; quanto à forma técnica, a instrução pública era formalizada por metodologias diversas, pelo ensino da leitura, escrita, cálculo aritmético e doutrina religiosa e também pela realização de exames periódicos para a avaliação dos alunos. Assim, as propostas de reforma da instrução pública de Rui Barbosa e João Köpke sugerem uma nova combinatória desse conjunto de elementos técnicos e institucionais da educação primária. Em vez de especificarem os termos da realização das práticas e da estrutura instalada, elas pretendiam reconstituir as prerrogativas e credenciais do sistema de ensino público. Nessa medida, o que propunham era estabelecer as possibilidades de funcionamento de uma estrutura de escolarização vinculada aos processos de regulação social vigentes. Nisso repousou uma diferença fundamental entre ambos: se para Rui Barbosa toda a população deveria, no período de obrigatoriedade, fazer parte desses processos, cabendo à escola selecionar aqueles que deveriam permanecer no sistema de ensino, para João Köpke o acesso à escola era já um momento da seleção social, devendo ingressar nela somente aqueles que tivessem recursos para responder às exigências de excelência do sistema de escolarização.

Em terceiro lugar, as considerações de Rui Barbosa e João Köpke, em torno da educação popular, sustentaram procedimentos importantes acerca da escolari- 
zação estatal e da sociedade. Rui Barbosa apoiou a idéia segundo a qual especialização e controle residem no governo central e na burocracia educacional. A predominância do Estado sobre as relações entre as diferentes instituições escolares levou os Pareceres a direcionarem a escolaridade para campos que favoreciam o controle centralizado e burocrático na regulamentação das normas e diretrizes do sistema educacional. A necessidade dessa direção para a organização oficial do ensino não é confirmada nos trabalhos de João Köpke. Neles a preocupação era evitar que o relacionamento entre as iniciativas individuais e as instituições escolares retrocedesse em direção ao poder central. Em contrapartida, existiu na Proposta e no Projeto uma série de enfoques no desenvolvimento metodológico e institucional da prática pedagógica e da organização escolar. João Köpke concentrou seus esforços na construção da autonomia das instituições escolares, sem deixar que os parâmetros contextuais da prática e da difusão escolares interferissem na orientação das reformas do ensino público.

Confrontados, esses textos, esses exemplos, ajudam a melhor interpretar os artifícios de um pensamento, de uma linguagem e de uma cultura política mais ocupados com a qualificação da idéia de cidadania do que com a sua promoção. Sua análise permite mostrar, sob as peripécias políticas e seus episódios, a distância que pode existir entre duas faces de um mesmo sistema de pensamento. Querer fazer da escolarização um instrumento de estabilidade social e desenvolvimento econômico foi o elo, a interseção, entre utopias distantes: por um lado, a construção de um sistema público de ensino que fizesse parte das práticas do governo para resolver complexas tensões e conflitos sociais e, por outro, a criação de instâncias autônomas perante os mecanismos de estatização das formas de educação, capazes de estabelecer instrumentos de controle social para as classes ricas sobre as classes populares. Não se quer com isso dizer que a estruturação do sistema de ensino acabou se revelando flexível às negociações de preferências e privilégios mas, tão-somente, relembrar que os procedimentos para essa estruturação foram desenvolvidos em meio a conflitos e disputas nitidamente marcados pelo jogo político dos anos 1868-1889.

\section{REFERÊNCIAS BIBLIOGRÁFICAS}

AGUIAR, A. P. Carta para o exercício de leitura rápida pelo methodo abreviado denominado Boncadafá adotado pelo governo Imperial na 3a Escola Publica da Freguezia de Sant'Anna na Corte do Rio de Janeiro. Rio de Janeiro: Pinheiro e Cia., I87I. 
BARBOSA, R. Obras completas de Rui Barbosa. Rio de Janeiro: Ministério da Educação e Saúde, 1946, v. 10, 4 t. Reforma do ensino primário e várias instituições complementares da instrução pública.

BARROS, R. S. M. de. A Evolução do pensamento de Pereira Barreto. São Paulo: Editorial Grijalbo, 1967.

A Ilustração brasileira e a idéia de universidade. São Paulo: Universidade de São Paulo, 1959. (Faculdade de Filosofia, Ciências e Letras, Boletim n. 24; História e Filosofia da educação n.2.)

BOMTEMPI JR., B. História da educação brasileira: o terreno no consenso. São Paulo, 1995. Dissert. (mestr.) PUC.

BOSI, A. Dialética da colonização. São Paulo: Cia das Letras, 1989. p. 194-245: O escravismo entre dois liberalismos.

CARVALHO, J. J. de A. Resposta ao Ofício de 09 de julho de 1880 (parecer acerca da obra "Livro novo para o ensino simultâneo da leitura e da escritura com o methodo phonetico"). Rio de Janeiro, I I jul. I 880. [Arquivo Geral da Cidade do Rio de Janeiro: Métodos de ensino (1852-1890); 10-4-20. ]

CONSTANT, B. Parecer sobre o graphoscopio. 22 abr. I 882. [Arquivo Geral da Cidade do Rio de Janeiro: Métodos de ensino (| 852- |890); 10-4-20.]

MARCONI, J. Correspondência de João Marconi ao poder público. Paraná, I 5 jun. I 880. [Arquivo Geral da Cidade do Rio de Janeiro: Métodos de ensino (I 852- | 890); 10-4-20.]

CURY, C. R. J. Cidadania republicana e educação: uma questão democrática no governo provisório de marechal Deodoro e no Congresso Constituinte de 1890-1891. Belo Horizonte, 1991. Tese de concurso para professor titular.

GONÇALVES, V. T. V. O Liberalismo demiurgo: estudo sobre a reforma educacional projetada nos pareceres de Rui Barbosa. São Paulo , 1994. Tese (dout.) Feusp.

HILSDORF, M. L. S. Francisco Range/ Pestana: jornalista, político, educador. São Paulo: 1986. Tese (dout.) Feusp.

Ensino mútuo na Província de São Paulo: primeiros apontamentos. In.:

BASTOS, M. H. C.; FARIA FILHO, L. M. A Escola elementar no século XIX: o ensino monitorial/ mútuo. Passo Fundo: Ediuf, 1999. p.197-215.

Cultura escolar/cultura oral em São Paulo (| 820- | 860). In: VIDAL, D. G.;

HILSDORF, M. L. S. Tópicas em história da educação. São Paulo: Edusp, 200 I . p.45-72.

KÖPKE, J. Projeto de reforma do ensino primario do Districto Federal. Rio de Janeiro, 24 dez. 1889. [Arquivo Geral da Cidade do Rio de Janeiro: Reforma do Ensino (I 854- | 906); 10-04-24.] 
KÖPKE, J. et al. Plano de reforma de ensino da Província do Paraná. In: MOACYR, P. A Instrução e as províncias. São Paulo: Companhia Editora Nacional, 1940.

LOURENÇO FILHO, M. B. A Pedagogia de Rui Barbosa. São Paulo: Melhoramentos, 1954. MATTOS, I. R. O Tempo Saquarema. São Paulo: Hucitec; Brasília-DF: INL, 1987.

NABUCO, J. Um Estadista do império: Nabuco de Araújo, sua vida, suas opiniões, sua época. Nova ed., t. 2. São Paulo: Cia. Editora Nacional; Rio de Janeiro: Civilização Brasileira, 1936.

NASCIMENTO, T. A. Q. R. Pedagogia liberal modernizadora: Rui Barbosa e os fundamentos da educação brasileira republicana. Campinas: Autores Associados, 1997.

PATTO, M. H. O Modo capitalista de pensar a escolaridade: anotações sobre o caso brasileiro. In:PATTO, M.H. (org.). A Produção do fracasso escolar. São Paulo: Queiroz, I 990. p.53- 127. REIS FILHO, C. A Educação e a ilusão liberal: origens da escola pública paulista. Campinas: Autores Associados, 1995.

SOUZA, M. C. C. C. A Escola e a memória. São Paulo: Edusf, 2000.

VIDAL, D. G.; SOUZA, M. C. A Memória e a sombra: a escola brasileira entre o Império e a República. Belo Horizonte: Autêntica, 1999.

WARDE, M. J.; CARVALHO, M. M. C. de. Política e cultura na produção da história da educação no Brasil. Contemporaneidade e Educação, v.5, n.7, p.9-33, 2000.

Recebido em: novembro 2002

Aprovado para publicação em: março 2003 